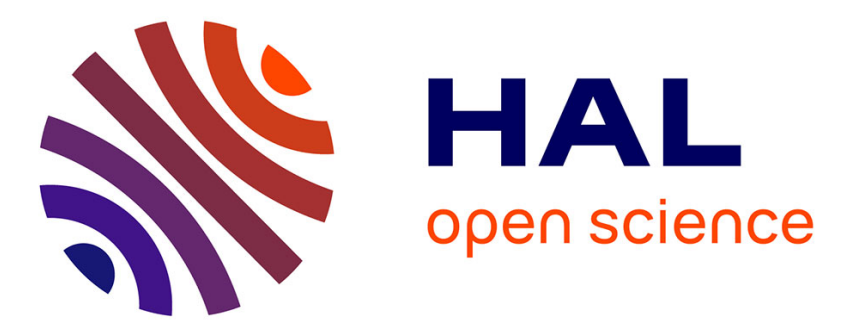

\title{
Simulated selection responses for breeding programs including resistance and resilience to parasites in Creole goats
}

Mélanie Gunia, Florence Phocas, Jean-Luc Gourdine, P. P. Bijma, Nathalie Mandonnet

\section{To cite this version:}

Mélanie Gunia, Florence Phocas, Jean-Luc Gourdine, P. P. Bijma, Nathalie Mandonnet. Simulated selection responses for breeding programs including resistance and resilience to parasites in Creole goats. Journal of Animal Science, 2013, 91 (2), pp.572-581. 10.2527/jas.2011-5071 . hal-01000064

\section{HAL Id: hal-01000064 https://hal.science/hal-01000064}

Submitted on 28 May 2020

HAL is a multi-disciplinary open access archive for the deposit and dissemination of scientific research documents, whether they are published or not. The documents may come from teaching and research institutions in France or abroad, or from public or private research centers.
L'archive ouverte pluridisciplinaire $\mathbf{H A L}$, est destinée au dépôt et à la diffusion de documents scientifiques de niveau recherche, publiés ou non, émanant des établissements d'enseignement et de recherche français ou étrangers, des laboratoires publics ou privés. 


\section{JOURNAL OF ANIMAL SCIENCE}

The Premier Journal and Leading Source of New Knowledge and Perspective in Animal Science

\section{Simulated selection responses for breeding programs including resistance and resilience to parasites in Creole goats}

M. Gunia, F. Phocas, J.-L. Gourdine, P. Bijma and N. Mandonnet

J ANIM SCI 2013, 91:572-581.

doi: 10.2527/jas.2011-5071 originally published online November 12, 2012

The online version of this article, along with updated information and services, is located on the World Wide Web at:

http://www.journalofanimalscience.org/content/91/2/572 


\title{
Simulated selection responses for breeding programs including resistance and resilience to parasites in Creole goats ${ }^{1,2}$
}

\author{
M. Gunia,* F. Phocas, $\uparrow$ J.-L. Gourdine, * P. Bijma, $\$$ and N. Mandonnet*3 \\ *Tropical Animal Science Unit, INRA UR 143, French National Institute for Agricultural Research, \\ 97170 Petit-Bourg, Guadeloupe, French West Indies; †Animal Genetics and Integrative Biology, \\ INRA UMR 1313, French National Institute for Agricultural Research, FR-78352 Jouy-en-Josas, France; \\ and $\$$ Animal Breeding and Genetics Group, Wageningen University, NL-6709 PG Wageningen, The Netherlands
}

\begin{abstract}
The Creole goat is a local breed used for meat production in Guadeloupe (French West Indies). As in other tropical countries, improvement of parasite resistance is needed. In this study, we compared predicted selection responses for alternative breeding programs with or without parasite resistance and resilience traits. The overall breeding goal included traits for production, reproduction, and parasite resilience and resistance to ensure a balanced selection outcome. The production traits were BW and dressing percentage (DP). The reproduction trait was fertility (FER), which was the number of doe kiddings per mating. The resistance trait was worm fecal egg count (FEC), which is a measurement of the number of gastro-intestinal parasite eggs found in the feces. The resilience trait was the packed cell volume (PCV), which is a measurement of the volume of red blood cells in the blood. Dressing percentage, BW, and FEC were measured at
\end{abstract}

11 mo of age, which is the mating or selling age. Fertility and PCV were measured on females at each kidding period. The breeding program accounting for the overall breeding goal and a selection index including all traits gave annual selection responses of $800 \mathrm{~g}$ for BW, $3.75 \%$ for FER, $0.08 \%$ for DP, $-0.005 \ln ($ eggs $/ g)$ for FEC, and $0.28 \%$ for PCV. The expected selection responses for $\mathrm{BW}$ and $\mathrm{DP}$ in this breeding program were reduced by $2 \%$ and $6 \%$, respectively, compared with a breeding program not accounting for FEC and PCV. The overall breeding program, proposed for the Creole breed, offers the best breeding strategy in terms of expected selection responses, making it possible to improve all traits together. It offers a good balance between production and adaptation traits and may present some interest for the selection of other goat breeds in the tropics.

Key words: goat, parasite, resilience, resistance, selection

(C) 2013 American Society of Animal Science. All rights reserved.

J. Anim. Sci. 2013.91:572-581

doi: $10.2527 /$ jas2011-5071

\section{INTRODUCTION}

In tropical countries, the high prevalence of gastro-intestinal parasites in sheep and goats has strong

\footnotetext{
${ }^{1}$ We gratefully acknowledge the financial support of the Guadeloupe Region, the European Union social Funds, and the European project FP7-KBBE-2009-1-1-02-3SR. We also thank Cabricoop board and technicians for their advice and Yanavy Suos for the English corrections.

${ }^{2}$ Disclaimer: The views expressed in this publication are the sole responsibility of the authors. The information in this document is provided as is and no guarantee or warranty is given that the information is fit for any particular purpose. The user thereof uses the information at its sole risk and liability.

${ }^{3}$ Corresponding author: nathalie.mandonnet@antilles.inra.fr

Received December 28, 2011.

Accepted October 26, 2012.
}

consequences on animal production and welfare. Parasites are responsible for greater mortality and reduced growth. To control parasite infection, anthelmintic products have been widely used during the last $40 \mathrm{yr}$, leading to the development of parasite strains resistant to these products (Kaplan, 2004). Alternative methods have been discussed to reduce the use of anthelmintics (Jackson and Miller, 2006), such as optimized nutrition, use of targeted selective treatment strategies, and grazing management. Selection of small ruminants based on their improved resistance against parasites is 1 of these methods (Eady et al., 2003). Genetic selection results in long-lasting, steady, and regular improvement. As in any tropical country, improvement of parasite resistance in the 
Creole goat breed is needed in Guadeloupe (French West Indies, latitude $16^{\circ} \mathrm{N}$, longitude $61^{\circ} \mathrm{W}$ ). This local breed, used for meat production, is reared on pasture where it is naturally infected by gastro-intestinal nematodes. Their prevalence (proportion of infected animals) reaches 80 to $100 \%$ and they are responsible for $80 \%$ of pre-weaning mortality (Aumont et al., 1997).

Resistance and resilience are 2 protection mechanisms against gastro-intestinal nematodes. Resistance is the ability to control parasite infections by suppressing their establishment, controlling their number, and regulating their life cycle. Resilience is the ability to tolerate parasites without developing clinical signs. Resilient animals suffer less performance loss under parasite challenge (Bisset and Morris, 1996).

Recently, a farmer association, extension services, and the Research Institute in Guadeloupe have collaborated to implement a breeding program for Creole goats. The breeding goal for Creole goats has already been derived (Gunia et al., 2012). It included production, reproduction, and parasite resistance and resilience traits with some uncertainty around the economic values of the resistance and resilience traits. In this study, we used deterministic prediction to compare selection responses for breeding goals integrating parasite resistance and resilience in different ways.

\section{MATERIALS AND METHODS}

Animal Care and Use Committee approval did not need to be obtained for this study as no animal was used.

\section{Creole Goat Breeding Goal}

Description of the Traits in the Breeding Program. The most complete breeding goal aimed at improving production, reproduction, and parasite resistance and resilience in the Creole goat population. The production traits were BW and dressing percentage (DP). The reproduction trait chosen was fertility (FER), which is the number of doe kiddings per mating. The resilience trait was the packed cell volume (PCV) of does, defined as the measurement of the volume of red cells in the blood used to diagnose anemia caused by hematophagous parasites such as Haemonchus contortus. The resistance trait was the worm fecal egg count (FEC) of 11 mo old kids, which is a measurement of the number of gastrointestinal parasite eggs found in the feces.

Whatever the breeding goal, the indirect expected selection response in litter size at birth (LS) was analyzed. This trait was neither included in the breeding goal nor in the selection index. No selection pressure was put on this trait because farmers were satisfied with the present level of LS (M. Gunia, unpublished data). However, the expected selection response in this trait was studied to assess its expected genetic trend, a biological and economical optimum value being hypothesized for the trait.

The indirect expected selection response in FEC of does was not analyzed in this study. However, we assumed that the response would vary in the same direction as FEC in kids due to the fairly high genetic correlations $(0.76)$ between the 2 measurements (Mandonnet et al., 2006).

Alternative Breeding Goals. In this study, we compared expected selection responses for alternative breeding goals including resistance or resilience traits in different ways. The economic values were previously derived by using a deterministic bio-economic model describing the profit of a Guadeloupean goat farm (Gunia et al., 2012). The economic values for all traits except FEC were the marginal variation of annual profit per mated doe, caused by the increase of 1 unit of the trait and keeping the other traits constant at the population mean. The economic value for FEC was derived by comparing the expected profit and average FEC in a normal situation and in an extreme situation where parasites had developed resistance to anthelmintics (Gunia et al., 2012).

The "Hbase" breeding goal was:

$$
\begin{aligned}
\text { Hbase }= & 7.69 \times \mathrm{A}_{\mathrm{BW}}+1.38 \\
& \times \mathrm{A}_{\mathrm{FER}}+3.53 \times \mathrm{A}_{\mathrm{DP}}
\end{aligned}
$$

The "Hresilience" breeding goal was:

$$
\begin{aligned}
\text { Hresilience }= & 7.69 \times \mathrm{A}_{\mathrm{BW}}+1.38 \times \mathrm{A}_{\mathrm{FER}} \\
& +3.53 \times \mathrm{A}_{\mathrm{DP}}+0.3 \times 10^{-4} \times \mathrm{A}_{\mathrm{PCV}}
\end{aligned}
$$

The "Hresistance" breeding goal was:

$$
\begin{aligned}
\text { Hresistance }= & 7.69 \times \mathrm{A}_{\mathrm{BW}}+1.38 \times \mathrm{A}_{\mathrm{FER}} \\
& +3.53 \times \mathrm{A}_{\mathrm{DP}}-18.85 \times \mathrm{A}_{\mathrm{FEC}}
\end{aligned}
$$

The "Hcombined" breeding goal, that included resistance and resilience traits, was:

$$
\begin{aligned}
\text { Hcombined }= & 7.69 \times \mathrm{A}_{\mathrm{BW}}+1.38 \times \mathrm{A}_{\mathrm{FER}} \\
& +3.53 \times \mathrm{A}_{\mathrm{DP}}+0.3 \times 10^{-4} \times \\
& \mathrm{A}_{\mathrm{PCV}}-18.85 \times \mathrm{A}_{\mathrm{FEC}}
\end{aligned}
$$

with $\mathbf{A}_{\mathbf{x}}$ denoting the true breeding value for trait X. The trait BW was expressed in $\mathrm{kg}$, FER in \%, DP in \%, PCV in $\%$, and FEC in natural logarithm of eggs per gram. The corresponding economic weights were given in euros per physical unit of the traits.

Except in 1 case (Hcombined without FEC and PCV included in the selection index), exactly the same traits were considered in the breeding goal and in the selection index of the breeding program. However, we studied the indirect expected selection response for each trait, 
though it was excluded from the breeding goal, as for instance responses in PCV and FEC when selection occurred for Hbase. Furthermore, the economic values of PCV and FEC being uncertain, we tested the sensitivity of the selection responses to changes of these economic values in the Hcombined breeding goal.

Additionally, we calculated the contribution $r^{2}$ of each trait $X$ to the genetic variance $\sigma^{2}{ }_{H}$ of the breeding goal $H$ :

$$
r_{x}^{2}=\frac{E V_{x}^{2} \times \sigma_{a X}^{2}}{\sigma_{H}^{2}}
$$

with EVx being the economic value of the trait $\mathrm{X}$ and $\sigma^{2}$ ax its genetic variance.

We also calculated the correlations between breeding goals:

$$
\begin{aligned}
& \text { Covariance }\left(H_{1}, H_{1}\right)=E V_{1}^{\top} \times \operatorname{Var}\left(A_{1}\right) \times E V, \\
& \text { Correlation }\left(H_{1}, H_{1}\right)=\frac{\operatorname{Covariance}\left(H_{1}, H_{1}\right)}{\sqrt{\sigma_{n}^{2} \times \sigma_{n}^{2}}}
\end{aligned}
$$

with $\mathbf{E V i} \mathbf{i}^{\mathrm{T}}$ being the row vector $(1 \times n)$ of economic values of the breeding goal $\mathrm{Hi}, \mathbf{E V} \mathbf{j}$ the column vector $(\mathrm{m} \times$ 1) of economic values of the breeding goal $\mathrm{Hj}, \operatorname{Var}\left(\mathbf{A}_{\mathrm{i}, \mathrm{j}}\right)$ the genetic variance-covariance matrix $(n \times \mathrm{m})$ of the traits in the breeding goals $\mathrm{Hi}$ and $\mathrm{Hj}$, and $\sigma_{\mathrm{H}}^{2}$ the variance of the breeding goal.

\section{Simulation Program}

We used the deterministic simulation program Se1Action (Rutten et al., 2002) to compare the expected selection responses of the different breeding goals. SelAction predicts selection response on pseudo-BLUP estimated breeding values and accounts for the reduction of variance due to selection (Bulmer, 1971). The program assumed random mating of the selected animals. In our study, we used SelAction with its option of overlapping generations and truncation selection.

\section{Description of the Selection Nucleus}

Organization of the Selection Nucleus. We simulated a selection nucleus of 300 Creole does that could be implemented in the near future. As no performance recording would occur in all the Creole goat population, we assumed that the nucleus would be closed. The best animals produced in the nucleus would be used for the renewal of the nucleus, whereas the other animals would either be culled or sold to other farmers (females for crossbreeding with bucks of specialized meat breeds such as Boer, males for pure breeding).

Reproduction in the Nucleus. First mating takes place at 11 mo. Only natural mating occurs, with a doe to buck ratio of 15 to 1 . Does are mated every 8 mo ( 5 mo of pregnancy and 3 mo of suckling), giving 3 litters in 2 yr. Hence, every 8 mo, a doe produces 1.6 kids that reach $11 \mathrm{mo}$. The number of kids was based on the following parameters: kidding rate of $82 \%$, litter size at birth of 2.3 kids, pre-weaning mortality of $18 \%$, and mortality between weaning and 11 mo of age of $14 \%$. An equal number of males and females was assumed to be born per litter (Gunia et al., 2012).

Nucleus Demography. The demography of the nucleus herd is shown in Fig. 1. The 300 does in the nucleus were divided into 7 age classes. There were $11 \%$ mortality between each age class and $9 \%$ of the does culled for age. The 20 bucks in the nucleus were divided into 3 age classes and 30\% were culled for age. An age class was 8 mo (interval between 2 kiddings). Every 8 mo, 6 bucks out of 20 and 90 does out of 300 in the nucleus were selected as parents of the next generation to renew the nucleus herd. They produced 60 young males and 60 young females. All the 60 females were integrated in the nucleus herd. Among the 60 young males, only 7 of them were selected to join the nucleus herd. Hence, there was 1 selection stage for females and there were 2 for males. These assumptions resulted in an average generation interval of 21 mo. For SelAction, the 2 selection stages for males could not be modeled directly with the overlapping generation option. SelAction only considers selection of the parents in the nucleus herd. Therefore, in the program, these 2 selection steps were combined into 1 and SelAction chose the 6 bucks selected as parents among 180 bucks in the nucleus herd (60 bucks per age class).

Information Sources. At 11 mo of age (age class 2), BW was recorded on all animals, FEC on males only, and DP on $50 \%$ of the unselected male half-sibs of the

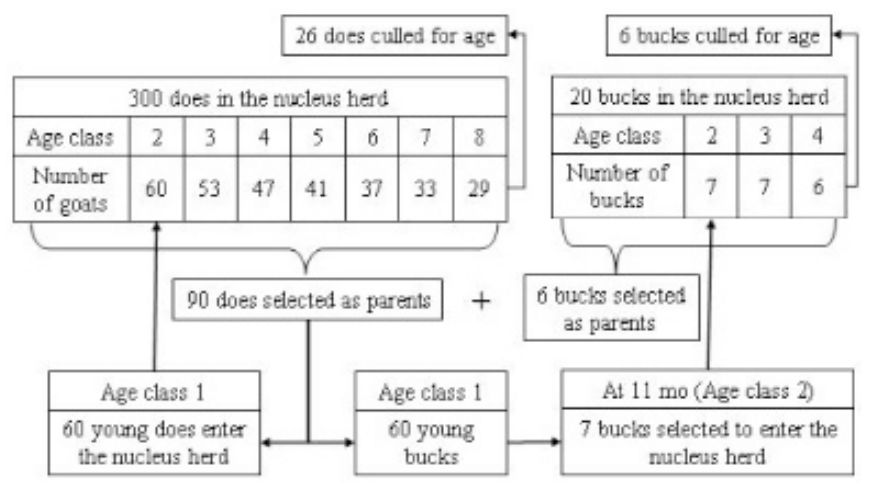

Figure 1. Dynamic and flock composition of the Creole nucleus herd for $8 \mathrm{mo}$. Age class $1=0$ to $8 \mathrm{mo}$, age class $2=8$ to $16 \mathrm{mo}$, etc. 
Table 1. Traits involved in Creole goats breeding program and their parameters ${ }^{1}$

\begin{tabular}{|c|c|c|c|c|}
\hline Trait & Abbreviation & Means & $\begin{array}{l}\text { Phenotypic } \\
\text { SD }\end{array}$ & $\begin{array}{l}\text { Genetic } \\
\text { SD }\end{array}$ \\
\hline $\mathrm{BW}$ at $11 \mathrm{mo}, \mathrm{kg}$ & BW & 17.9 & 3.4 & 1.9 \\
\hline Fertility, \% & FER & 82.9 & 37.5 & 12.3 \\
\hline $\begin{array}{l}\text { Dressing percentage (DP) } \\
\text { at } 11 \mathrm{mo}, \%\end{array}$ & DP & 40.0 & 2.1 & 1.2 \\
\hline Packed Cell Volume, \% & $\mathrm{PCV}$ & 24.1 & 4.5 & 1.6 \\
\hline $\begin{array}{l}\text { Fecal Egg Count at } 11 \mathrm{mo} \text {, } \\
\ln (\text { eggs } / \mathrm{g})\end{array}$ & FEC & 6.4 & 0.9 & 0.4 \\
\hline Litter Size, kids & LS & 2.1 & 0.7 & 0.2 \\
\hline
\end{tabular}

even selection candidates. At each delivery period, starting at 16 mo of age (age class 3), FER and PCV were recorded on all females in the nucleus herd. The BLUP information was available for all selection candidates on all traits and in all age classes.

\section{Genetic and Phenotypic Parameters}

Original Set of Correlations. The full set of correlations, means, SD, and heritability estimates used in this study (Tables 1 and 2) came from different sources. Gunia et al. (2011) derived the genetic and phenotypic parameters of BW, FER, LS, PCV, and FEC in the Creole goats. Literature provided estimates of the parameters derived for DP in sheep breeds, because no estimates in goat breeds were found. Heritability of DP was the mean of estimates given by Safari and Fogarty (2003), Ermias et al. (2006), and Greeff et al. (2008). The genetic variance of DP as well as the genetic and phenotypic correlations between BW and DP came from Greeff et al. (2008). The genetic and phenotypic correlations between LS and DP were given by Safari et al. (2008). We did not find any estimates of the correlations between FER and DP, FEC and DP, and PCV and DP in the literature. We therefore assumed that the correlations between FER and DP were equal to the correlations between the number of lambs born per ewe joined and DP as given by Safari et al. (2008). For the correlations of DP with FEC or PCV, we applied the following hypotheses:

$$
\begin{aligned}
\text { Correlation FEC-DP } \approx & (\text { correlation FEC-BW }) \\
& \times(\text { correlation BW-DP }) \\
\text { Correlation PCV-DP } \approx & (\text { correlation PCV-BW }) \\
& \times(\text { correlation BW-DP })
\end{aligned}
$$

In both cases, the phenotypic and genetic correlations estimates were close to $0(<0.05)$. We therefore set them to 0 . The genetic and phenotypic (co)variances matrices were checked to ensure that they were positive definite, meaning all the eigenvalues were above 0 .

Sensitivity Analysis of the Genetic Correlations. We performed a sensitivity analysis of some key genetic correlations: PCV-FEC, BW-PCV, BW-FEC, in the Hcombined breeding goal. We chose to test these correlations because of their importance for the selection responses in PCV or FEC. We made each genetic correlation vary from $-2 \mathrm{SE}$ to $+2 \mathrm{SE}$ around its initial estimate and kept the other correlations at a constant value. The new genetic variance-covariance matrices obtained were checked to ensure that they were positive definite. Whenever this was not the case, selection responses were not calculated.

\section{RESULTS}

\section{Comparison of Breeding Goals}

We compared the economic responses of alternative breeding goals. The breeding goals were highly correlated (Table 3). The inclusion of PCV in the breeding goal did not change the variance of the breeding goal, due to the very low economic value of PCV. Therefore, all breeding goals globally showed similar expected selection responses (Table 4). The greatest economic response based on all traits (Hcombined) logically occurred when all traits were included in the breeding goal and in the selection index of the breeding program. The greatest

Table 2. Genetic correlations (above the diagonal), phenotypic correlations (below the diagonal), and heritability estimates (on the diagonal) for traits involved in the Creole goat breeding program ${ }^{1}$

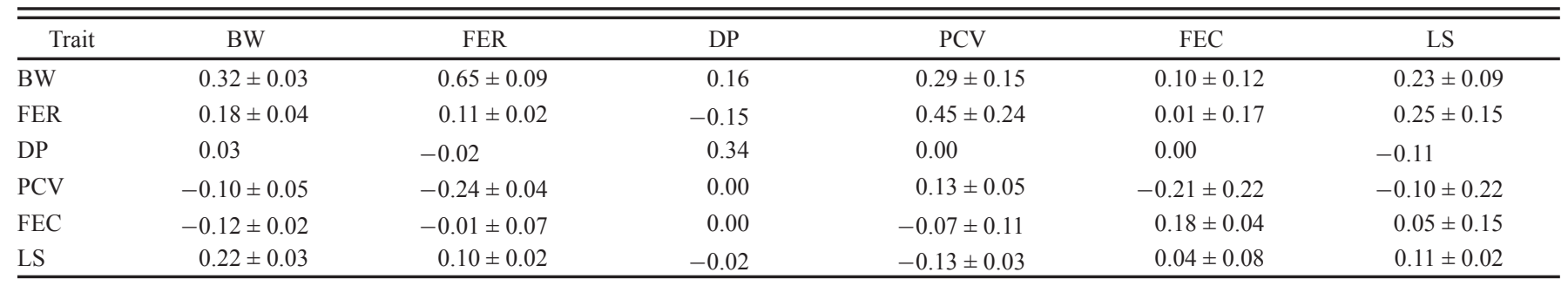

\footnotetext{
${ }^{1}$ Parameters were derived for Creole goat breed for all traits except DP. Heritability and correlations estimates for DP were derived for sheep breeds in the literature. Traits: $\mathrm{BW}=\mathrm{BW}$ at $11 \mathrm{mo}(\mathrm{kg}), \mathrm{FER}=$ fertility $(\%), \mathrm{DP}=$ dressing percentage at $11 \mathrm{mo}(\%), \mathrm{PCV}=$ packed cell volume $(\%)$, FEC = fecal egg count at $11 \mathrm{mo}[\ln (\mathrm{eggs} / \mathrm{g})], \mathrm{LS}=$ litter size (kids).
} 
Table 3. Correlations between the alternative breeding goals for the Creole goat breed ${ }^{1}$

\begin{tabular}{lccc}
\hline \hline Item & Hcombined & Hresilience & Hresistance \\
\hline Hbase & 0.97 & 1.00 & 0.97 \\
Hcombined & & 0.97 & 1.00 \\
Hresilience & & & 0.97 \\
\hline
\end{tabular}

${ }^{1}$ Hbase $=$ breeding goal including BW, fertility, and dressing percentage. Hcombined $=$ Hbase + packed cell volume + fecal egg count. Hresilience $=$ Hbase + packed cell volume. Hresistance $=$ Hbase + fecal egg count.

economic response based on production and reproduction traits (Hbase) occurred in the Hresilience breeding program, due to the greatest selection responses expected for BW and FER caused by the favorable genetic correlations of PCV with BW and FER. Calculation of $r^{2}$ of each trait enabled the comparison of the proportion of variance explained by the trait in the breeding goals. For all breeding goals, we obtained similar $r^{2}$ with $33 \%$ for FER, $25 \%$ for BW, $6 \%$ for FEC, $2 \%$ for DP, and $0 \%$ for PCV. These results clearly show that FER and BW dominate the breeding goals. They obtained the greatest genetic gains for traits standardized per genetic standard deviation (Fig. 2) with about $800 \mathrm{~g} / \mathrm{yr}$ for BW and $3.7 \% / y r$ for FER for all breeding goals. Expected selection response for DP and LS was always positive.

We also valued individual responses for PCV and FEC because of the uncertainty around the calculation of the economic values of these traits. The alternative breeding goals being very close, we prefer to select on a breeding goal that ensures favorable selection responses in both resistance and resilience traits. The expected selection response for PCV was always positive. However, differences in the direction of selection response were observed

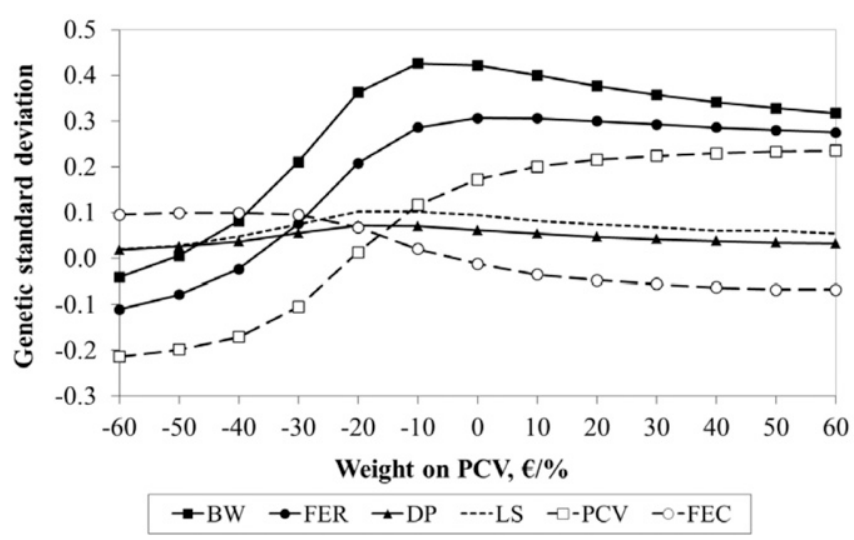

Figure 2. Expected selection responses per year in genetic SD according to the weight of PCV in the Hcombined breeding goal. Hcombined $=7.69 \times$ $\mathrm{A}_{\mathrm{BW}}+1.38 \times \mathrm{A}_{\mathrm{FER}}+3.53 \times \mathrm{A}_{\mathrm{DP}}+0.3 \times 10^{-4} \times \mathrm{A}_{\mathrm{PCV}}-18.85 \times \mathrm{A}_{\mathrm{FEC}}$, where $\mathrm{A}$ is the true breeding value, $\mathrm{FER}=$ Fertility, $\mathrm{DP}=$ dressing percentage, $\mathrm{LS}=$ litter size, $\mathrm{PCV}=$ packed cell volume, $\mathrm{FEC}=$ fecal egg count.

for FEC according to the breeding design. These results clearly show that FEC should be taken into account both in the breeding goal and in the selection index to be improved (i.e., to obtain a decrease in FEC). The need to record FEC may be explained by the unfavorable positive genetic correlation between FEC and BW and the low genetic correlations between FEC and the other traits.

In light of these results, the Hcombined breeding goal linked to a selection index including both PCV and FEC appears to be the best breeding strategy in terms of expected selection responses. This scenario improves both parasite resistance and resilience. Compared with the Hresilience breeding program, the Hcombined breeding program has a slightly lower economic selection response for the production and reproduction traits, but offers a favorable selection response for FEC. Com-

Table 4. Expected selection responses in the nucleus herd of Creole goats for alternative breeding programs

\begin{tabular}{|c|c|c|c|c|c|}
\hline \multirow[b]{2}{*}{ Trait $^{1}$} & \multicolumn{5}{|c|}{ Optimized breeding program for goal } \\
\hline & Hbase $^{2}$ & $\begin{array}{l}\text { Hcombined } \\
\text { PCV and FEC } \\
\text { not recorded }\end{array}$ & Hcombined & Hresilience & Hresistance \\
\hline BW & 0.816 & 0.816 & 0.798 & 0.818 & 0.798 \\
\hline FER & 3.668 & 3.674 & 3.753 & 3.783 & 3.630 \\
\hline FEC & 0.015 & 0.015 & -0.005 & 0.014 & -0.003 \\
\hline LS & 0.023 & 0.023 & 0.021 & 0.021 & 0.023 \\
\hline \multicolumn{6}{|c|}{ Expected economic response per year in economic units $(€)^{3}$} \\
\hline For Hbase trait set & 11.617 & 11.625 & 11.581 & 11.777 & 11.421 \\
\hline For Hcombined trait set & 11.334 & 11.342 & 11.665 & 11.523 & 11.478 \\
\hline
\end{tabular}

${ }^{1} \mathrm{BW}=\mathrm{BW}$ at $11 \mathrm{mo}(\mathrm{kg}), \mathrm{FER}=$ fertility $(\%), \mathrm{DP}=$ dressing percentage at $11 \mathrm{mo}(\%), \mathrm{PCV}=$ packed cell volume $(\%), \mathrm{FEC}=$ fecal egg count at $11 \mathrm{mo}[\mathrm{ln}$ (eggs/g)], LS = litter size (kids).

${ }^{2}$ Hbase $=$ breeding goal including BW, FER, DP. Hcombined $=$ Hbase + PCV + FEC. Hresilience $=$ Hbase + PCV. Hresistance $=$ Hbase + FEC.

${ }^{3}$ Calculated for production and reproduction traits (Hbase trait set) or for all traits (Hcombined trait set) according to the simulated breeding program (optimization of the selection index according to a given breeding goal and information sources). It is calculated as: $\sum_{\mathrm{i}}$ (Expected selection response in trait unit ${ }_{\mathrm{i}}$ *Economic value ${ }_{\mathrm{i}}$ ) with $\mathrm{i}$ being the considered traits. 
pared with the Hbase breeding program, expected selection response in the Hcombined breeding program is increased by $2 \%$ for FER and decreased by only $2 \%$ for BW and $6 \%$ for DP. Therefore, the economic selection response for BW, FER, and DP in the Hcombined scenario is only decreased by $0.3 \%$, meaning that optimal selection on Hcombined gave almost the same economic response for these traits than direct selection on Hbase.

\section{Changing Weight on PCV or FEC}

We tested the sensitivity of the selection responses to changes in PCV or FEC economic values in the Hcombined breeding goal, because these economic values were uncertain (Gunia et al., 2012). Changing the weight on PCV (Fig. 2) had more consequences on BW, FER, and FEC selection responses than on DP and LS selection responses, due to the difference in magnitude of the genetic correlations of these traits with PCV. Selection responses on BW, FER, and PCV collapsed and selection response for FEC increased when considering low economic value on PCV. The maximum expected selection response for all traits (except PCV) occurred when the economic value of PCV was close to 0 . A high positive weight on PCV was favorable for PCV and FEC but unfavorable for BW, FER, and DP.

Changing the weight on FEC in the Hcombined scenario (Fig. 3) had more consequences on BW, FER, and PCV selection responses than on DP and LS. High negative weight on FEC had favorable consequences on FEC and PCV selection responses, whereas selection responses for the other traits declined. The optimal response for all traits except FEC occurred when the economic value of FEC was close to 0 . However, a weight of 0 on FEC led to an unfavorable rise in selection response for this trait. The original economic value of -18.85 had the advantage of improving FEC with almost no decrease in expected selection responses on the other traits.

Given the nature of these results, it would appear that the initial estimates of economic values of $0.3 \times$ $10^{-4}$ for PCV and -18.85 for FEC were close to the optimum in terms of selection responses for all traits. Using these economic values resulted in favorable selection response for FEC and PCV with little loss in selection responses for BW, FER, and LS. Because of the uncertainty of the economic values of FEC and PCV, we would have moved from an economic evaluation to a desired gains evaluation if selection responses on these traits had been unfavorable.

\section{Sensitivity Analysis of the Genetic Correlations}

The genetic correlation estimated between PCV and FEC was -0.21 , with a SE of 0.22 . The sensitivity analy-

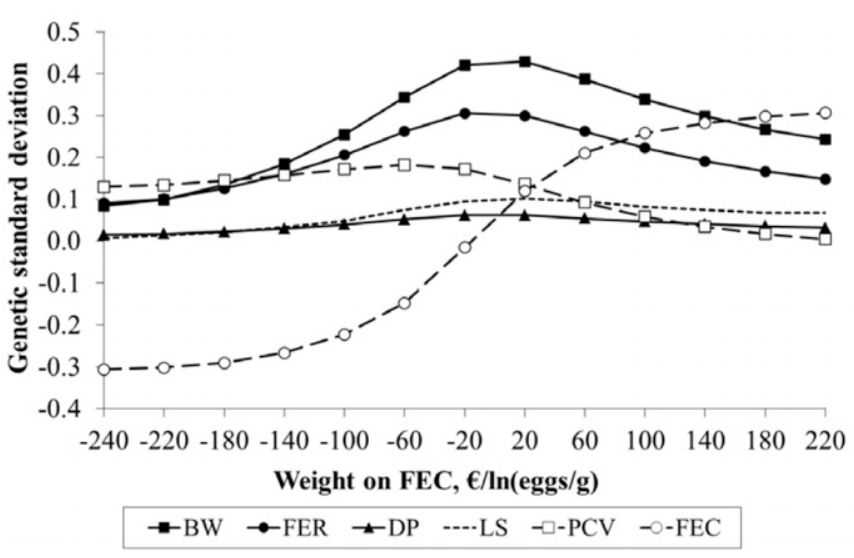

Figure 3. Expected selection responses per year in genetic SD according to the weight of FEC in the Hcombined breeding goal. Hcombined $=7.69 \times$ $\mathrm{A}_{\mathrm{BW}}+1.38 \times \mathrm{A}_{\mathrm{FER}}+3.53 \times \mathrm{A}_{\mathrm{DP}}+0.3 \times 10^{-4} \times \mathrm{A}_{\mathrm{PCV}}-18.85 \times \mathrm{A}_{\mathrm{FEC}}$, where $\mathrm{A}$ is the true breeding value, $\mathrm{FER}=$ Fertility, $\mathrm{DP}=$ dressing percentage, $\mathrm{LS}=$ litter size, $\mathrm{PCV}=$ packed cell volume, $\mathrm{FEC}=$ fecal egg count.

sis of this correlation in Hcombined scenario showed very few changes in expected selection responses. The expected selection response varied less than 0.02 genetic SD for FEC and less than 0.05 genetic SD for PCV. The most favorable selection responses occurred when considering the lowest genetic correlation between PCV and FEC.

We analyzed the sensitivity of the genetic correlations between BW and PCV or FEC in the Hcombined scenario. The correlation estimated between $\mathrm{BW}$ and PCV was 0.29 , with a SE of 0.15 . Selection response was very stable for all traits except PCV (Fig. 4). Expected selection response for PCV varied by 0.23 SD but always remained positive. A high correlation between $\mathrm{BW}$ and PCV gave a better selection response for PCV.

The correlation estimated between BW and FEC was 0.10 , with a SE of 0.12. Expected selection response was very stable for all traits except FEC, which varied by almost 0.2 SD (Fig. 5). High genetic correlation between $\mathrm{BW}$ and FEC led to a rise in FEC. Hence, if the true genetic correlation between $\mathrm{BW}$ and $\mathrm{FEC}$ is greater than our estimate of 0.10 , resistance to parasites will deteriorate. This result clearly shows the importance of an accurate estimation of the genetic correlation between BW and FEC.

\section{DISCUSSION}

\section{Evaluation of the Breeding Program}

Breeding Goal Choice. This research sought to use SelAction software to compare expected selection responses for alternative breeding goals including parasite resistance or resilience traits. The alternative breeding goals were highly correlated and offered similar expected selection responses. Nevertheless, the Hcombined scenario, which included production, reproduction, parasite resistance and resilience traits, offered the best breeding strategy in terms of expected selection responses, mak- 


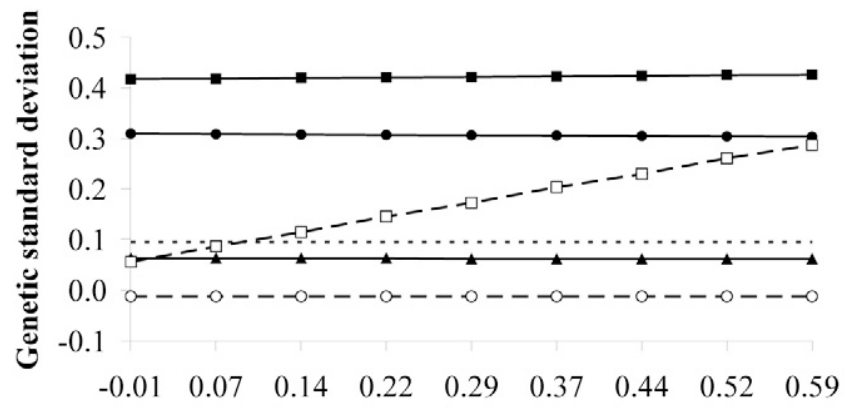

Genetic correlation BW-PCV

$\rightarrow \mathrm{BW} \rightarrow \mathrm{FER} \rightarrow \mathrm{DP} \cdots \mathrm{LS} \rightarrow \mathrm{PCV} \rightarrow \mathrm{FEC}$

Figure 4. Expected selection responses per year in genetic SD according to the genetic correlation between $\mathrm{BW}$ and PCV in the Hcombined breeding goal. Hcombined $=7.69 \times \mathrm{A}_{\mathrm{BW}}+1.38 \times \mathrm{A}_{\mathrm{FER}}+3.53 \times \mathrm{A}_{\mathrm{DP}}+0.3 \times$ $10^{-4} \times \mathrm{A}_{\mathrm{PCV}}-18.85 \times \mathrm{A}_{\mathrm{FEC}}$, where $\mathrm{A}$ is the true breeding value, $\mathrm{FER}=$ Fertility, $\mathrm{DP}=$ dressing percentage, $\mathrm{LS}=$ litter size, $\mathrm{PCV}=$ packed cell volume, $\mathrm{FEC}=$ fecal egg count.

ing it possible to improve all traits together. Compared with a breeding goal and selection index without PCV and FEC (Hbase scenario), the Hcombined breeding goal gave a greater expected selection response for FER in addition to the improvement of PCV and FEC, even if there was a little loss in expected selection responses for $\mathrm{BW}$ and DP. Therefore the economic response for BW, FER, and DP was almost unchanged.

Selection Responses. The Hcombined breeding goal brings high genetic gain for BW and FER. These 2 traits dominate the breeding objective. Hcombined brings also a moderate genetic gain for DP and a slow increase in LS. In meat breeds of sheep, Gicheha et al. (2007) and Gizaw et al. (2009) obtained similar expected selection responses for yearling BW with $760 \mathrm{~g} / \mathrm{yr}$ and $704 \mathrm{~g} / \mathrm{yr}$, respectively. The high standardized selection

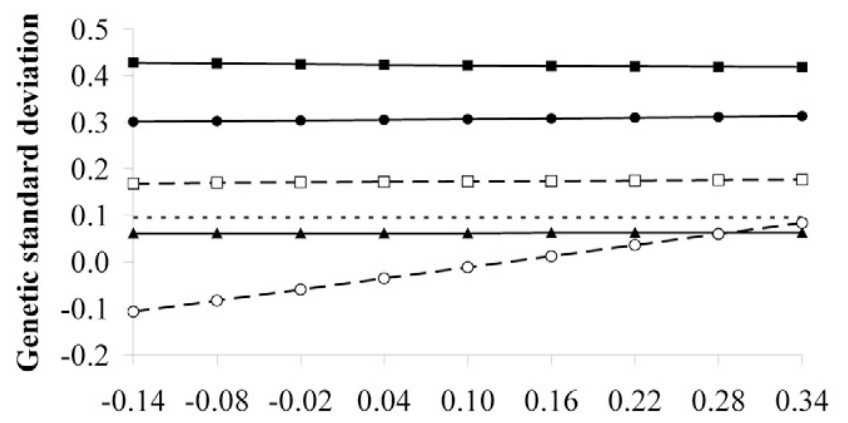

Genetic correlation BW-FEC

$$
\rightarrow \mathrm{BW} \rightarrow \mathrm{FER} \rightarrow \mathrm{DP} \cdots \mathrm{LS} \rightarrow \mathrm{PCV} \multimap-\mathrm{FEC}
$$

Figure 5. Expected selection responses per year in genetic SD according to the genetic correlation between $\mathrm{BW}$ and FEC in the Hcombined breeding goal. Hcombined $=7.69 \times \mathrm{A}_{\mathrm{BW}}+1.38 \times \mathrm{A}_{\mathrm{FER}}+3.53 \times \mathrm{A}_{\mathrm{DP}}+0.3 \times$ $10^{-4} \times \mathrm{A}_{\mathrm{PCV}}-18.85 \times \mathrm{A}_{\mathrm{FEC}}$, where $\mathrm{A}$ is the true breeding value, $\mathrm{FER}=\mathrm{Fer}-$ tility, $\mathrm{DP}=$ dressing percentage, $\mathrm{LS}=$ litter size, $\mathrm{PCV}=$ packed cell volume, $\mathrm{FEC}=$ fecal egg count. responses on BW and FER are very important for farmers and confirm that the Hcombined breeding goal fits the interest of the farmers (Gunia et al., 2010). The slow increase in LS is also a positive result. Farmers are indeed satisfied with the present litter size in Creole goats and do not wish to change it. The Hcombined breeding goal also gives favorable expected selection responses for PCV $(0.28 \% / y r)$ and FEC $(-0.005 \ln ($ eggs $/ g) / y r)$. To our knowledge, there is no study of selection response on PCV. Other authors did predict a favorable selection response for FEC in sheep when considering different breeding goals. Gicheha et al. (2007) considered breeding goals including FEC, litter size, lambing frequency, survival rate, BW, and consumable meat. Kominakis and Theodoropoulos (1999) considered a breeding goal including FEC, fat yield, and number of lambs weaned. In practice, Kahn et al. (2003) and Williams et al. (2010) obtained a significant reduction in FEC for sheep actually bred for parasite resistance.

\section{Economic Value and Genetic Correlations of Resistance and Resilience traits}

Economic Value of FEC and PCV. Assigning an economic value to FEC and PCV was not straightforward. For these traits, the economic loss caused by the deterioration of these traits was not linear, which made it difficult to derive their economic values. Weights on parasite resistance traits have usually been attributed according to the desired gain method (Kominakis and Theodoropoulos, 1999; Gicheha et al., 2005). As for the Creole goats, the economic value of PCV only accounted for the cost of anthelmintic treatments, which was very low (Gunia et al., 2012). The economic value was therefore very low and did not take into account all the consequences of parasite infection (such as productivity losses). On the other hand, the economic value of FEC accounted for production losses caused by extremely high levels of parasite infection, when parasites were no longer controlled by any treatments (e.g., in case of parasites resistant to anthelmintics). The economic value of FEC was therefore very high. As a result, we originally believed that the economic value of PCV was underestimated and the economic value of FEC was overestimated (Gunia et al., 2012). If selection responses on these 2 traits had been unfavorable, we would have considered the possibility of shifting from an economic perspective to one of desired gain. However this is not the case here; these economic values give optimal selection responses, with a favorable selection response on PCV and FEC and only 2 to $6 \%$ losses in BW and DP, respectively.

In contrast to our results, other authors have shown trade-offs between production and adaptation traits. The amplitude of the loss in selection response in production 
traits depends on the genetic correlations between traits and the level of the economic value on adaptation traits. Gizaw (2008) showed a loss in selection response of 25 to $58 \%$ in production traits to obtain the desired changes in FEC. When the genetic correlation between FEC and production trait was unfavorable and the weight on FEC was very high, Kominakis and Theodoropoulos (1999) observed dramatic losses in responses for production traits. Gicheha et al. (2005) stated that the level of disease prevalence and the type of systems (low or high input) should determine the economic value of FEC to adopt the best balance between production and disease resistance. Low input systems would choose a large negative economic value to ensure a reduction in FEC, whereas high input systems could handle positive and unfavorable response in FEC. The Creole goats are reared in low to medium input systems, with a very high prevalence of parasite infection. Therefore, a reduction in FEC is preferable.

Importance of Genetic Correlations with FEC. Our results have shown that FEC should be both in the breeding goal and recorded to be improved. Contrary to PCV, the indirect selection response does not allow any progress on FEC in the Creole goat population. Kominakis and Theodoropoulos (1999) and Gicheha et al. (2007) also observed significant additional response in parasite resistance when FEC was included in the index. However, Gicheha et al. (2007) obtained favorable selection response in FEC even without recording this trait, due to favorable negative correlations between FEC and the other traits in the breeding objective. As observed by Kominakis et al. (1997), the genetic correlations between FEC and the other traits are very important. The sensitivity analysis of the genetic correlation between BW and FEC confirmed this observation. Direction of selection response for FEC varied according to the value of this correlation.

\section{Consequences of Selection on Resistance and Resilience}

Genetic selection on FEC reduces worm egg output (Blaes et al., 2010), which leads to reduced pasture larval contamination, and therefore reduced subsequent larval challenge and infection (Bishop and Stear, 2003). It was originally believed that selecting for low FEC would increase BW. However, this predicted increase in productivity has not been attained often (Greer, 2008). Even if productivity gains are hypothetical, it seems reasonable to assume some reduction in the number of anthelmintic treatments, as occurred in Merino sheep selected for low FEC (Kahn et al., 2003). Moreover, it seems that parasites could not adapt quickly against the resistance mechanisms that their host has developed because parasites resistance seems to be determined by many genes with relatively small effects (Kemper et al.,
2009). Therefore, selection on parasite resistance is a good alternative to anthelmintic treatments.

Selection on resilience is a method that does not apply any selection pressure on parasites, which can complete their life cycle unimpeded. Resilient animals can cope better with the challenge in terms of productivity (Bisset and Morris, 1996). In opposition to selection on resistance, production benefits can be expected from selection on resilience. When Haemonchus is the predominant parasite, $\mathrm{PCV}$ is a satisfactory measurement of resilience (Baker et al., 2001).

Selection on resistance and resilience are clearly complementary. Selection on resistance and resilience will have long-lasting effects on animal health and welfare by reducing infection and consequences of infection. In the future, selection and other integrated methods of control will make it possible to no longer use anthelmintic treatments.

\section{Recording FEC and PCV}

The desire of farmer to participate in recording and selecting on parasite resistance and resilience is a crucial point. At present, farmers are not fully aware of the importance of these traits (Gunia et al., 2010). They mostly rely on anthelmintic products, even if parasites develop resistance to the treatments.

From a technical point of view, recording FEC and $\mathrm{PCV}$ is more difficult than recording weight or kidding success because fecal and blood samples have to be taken on farm and analyzed in a laboratory. From a short-term economical point of view, costs of recording PCV and FEC in the Hcombined scenario will be greater than the expected gain of $€ 0.32$ per year for the nucleus herd. Nevertheless, in the long term, recording FEC is important to avoid any unwanted side effects of selection, such as deterioration of this trait. Genetic parasite resistance could be a critical point in the near future, especially if anthelmintic products lose their efficiency. Therefore, recording FEC (at minima) or FEC and PCV is advisable.

The replacement of PCV measurement by the Famacha score could be a solution. The Famacha method is a measurement of the ocular conjunctivae color which allows selective drenching of only anemic animals (Bath et al., 1996). A study in Merino sheep has shown that the Famacha score was moderately heritable and highly correlated with PCV (Riley and Van Wyk, 2009). Detection of anemic animals with this method has proven to be very reliable under high Haemonchus challenge in goats (Rinaldi and Cringoli, 2012). In Creole goats, this method has been successfully implemented to reduce the number of anthelmintic treatments and could be compared with the measurement of anemia using PCV (Mahieu et al., 2007). The Famacha score is easy 
to measure and does not require any equipment (Besier, 2012). If this method is used by farmers to reduce the number of treatments, this score would become a more comprehensive tool for selection on resilience than PCV.

\section{A Sustainable Breeding Program}

Sustainable selection should be directed to cater for unpredictable futures (Smith, 1985) and require a broader definition of breeding goals. Breeding objectives should not only aim at greater production, but also at balancing production and adaptation to specific conditions (Gizaw et al., 2011). Animal breeding only determined by shortterm market forces may result in unwanted side effects concerning animal adaptation, whereas societal concern is growing for animal welfare and reduction of chemical medication (Olesen et al., 2000).

In developed and developing countries, gastro-intestinal nematodes remain one of the major threats affecting goat production (Hoste et al., 2010). Their infections are responsible for high mortality rate, reduced growth rate, reduced reproductive performance, and general loss of productivity (Perry et al., 2002). In Guadeloupe, a reduction of goat farm profit by $81 \%$ was observed when parasite infections were no longer controlled by anthelmintics (Gunia et al., 2012).

Many goat and sheep breeds have developed resistance or resilience to parasite infections, such as the Nigerian West African Dwarf goats (Chiejina and Behnke, 2011) or the Creole goats (Mandonnet et al., 1997). Baker and Gray (2004) observed that they were generally local tropical breeds perceived as unimproved. They have evolved in the face of continued challenge and become more resistant or resilient compared with other breeds (Bishop and Morris, 2007). Breeding program for nematode resistance are most likely to be based on these breeds, followed by selection on traits such as growth rate in the face of challenge, FEC, and anemia (Bishop, 2012).

Therefore, such breeding program for Creole goats could be of great interest for the selection of other breeds of goat in the tropics. This program offers a good balance between immediate and long-term profit, with the reduction of anthelmintic products. It will be a good example of in situ conservation of a local breed emphasizing parasite resistance and resilience.

\section{LITERATURE CITED}

Aumont, G., R. Pouillot, R. Simon, G. Hostache, H. Varo, and N. Barré. 1997. Digestive parasitism of small ruminants in the French West Indies. Prod. Anim. 10:79-89.
Baker, R. L., J. O. Audho, E. O. Aduda, and W. Thorpe. 2001. Genetic resistance to gastro-intestinal nematode parasites in Galla and Small East African goats in the sub-humid tropics. Anim. Sci. 73:61-70.

Baker, R. L., and G. D. Gray. 2004. Appropriate breeds and breeding schemes for sheep and goats in the tropics. In: R. A. Sani, G. D. Gray, and R. L. Baker, editors, Worm Control for Small Ruminants in Tropical Asia. Monogr. No. 113, Aust. Cent. for Int. Agric. Res., Canberra, ACT. p. 63

Bath, G. F., F. S. Malan, and J. A. Van Wyk. 1996. The "FAMACHA" Ovine Anaemia Guide to assist with the control of haemonchosis. In: Proc. 7th Annual Congress of the Livestock Health and Production Group of the South African Veterinary Association, Port Elizabeth, South Africa.

Besier, R. B. 2012. Refugia-based strategies for sustainable worm control: Factors affecting the acceptability to sheep and goat owners. Vet. Parasitol. 186:2-9.

Bishop, S. C. 2012. Possibilities to breed for resistance to nematode parasite infections in small ruminants in tropical production systems. Animal 6:741-747.

Bishop, S. C., and C. A. Morris. 2007. Genetics of disease resistance in sheep and goats. Small Rumin. Res. 70:48-59.

Bishop, S. C., and M. J. Stear. 2003. Modeling of host genetics and resistance to infectious diseases: Understanding and controlling nematode infections. Vet. Parasitol. 115:147-166.

Bisset, S.A., and C.A. Morris. 1996. Feasibility and implications of breeding sheep for resilience to nematode challenge. Int. J. Parasitol. 26:857-868.

Blaes, J.-L., N. Mandonnet, R. Arquet, and M. Mahieu. 2010. A long term experiment of integrated control of nematode parasitism in Creole goats. Adv. Anim. Biosci. 1:413-414.

Bulmer, M. G. 1971. The effect of selection on genetic variability. Am. Nat. 105:201-211.

Chiejina, S. N., and J. M. Behnke. 2011. The unique resistance and resilience of the Nigerian West African Dwarf goat to gastrointestinal nematode infections. Parasites Vectors. 4:12.

Eady, S. J., R. R. Woolaston, and I. A. Barger. 2003. Comparison of genetic and nongenetic strategies for control of gastrointestinal nematodes of sheep. Livest. Prod. Sci. 81:11-23.

Ermias, E., A. Yami, and J. E. O. Rege. 2006. Slaughter characteristics of Menz and Horro sheep. Small Rumin. Res. 64:10-15.

Gicheha, M. G., I. S. Kosgey, B. O. Bebe, and A. K. Kahi. 2005. Economic values for resistance to gastrointestinal helminths in meat sheep in Kenya. J. Anim. Breed. Genet. 122:165-171.

Gicheha, M. G., I. S. Kosgey, B. O. Bebe, and A. K. Kahi. 2007. Efficiency of alternative schemes breeding for resistance to gastrointestinal helminths in meat sheep. Small Rumin. Res. 69:167-179.

Gizaw, S. 2008. Sheep resources of Ethiopia: Genetic diversity and breeding strategy. PhD Diss. Wageningen Univ., Wageningen, the Netherlands.

Gizaw, S., H. Komen, O. Hanote, J. A. M. van Arendonk, S. Kemp, A. Haile, O. Mwai, and T. Dessie. 2011. Characterization and conservation of indigenous sheep genetic resources: A practical framework for developing countries. ILRI Res. Rep. No. 27. Nairobi, Kenya.

Gizaw, S., H. Komen, and J. A. M. van Arendonk. 2009. Optimal village breeding schemes under smallholder sheep farming systems. Livest. Sci. 124:82-88.

Greeff, J. C., E. Safari, N. M. Fogarty, D. L. Hopkins, F. D. Brien, K. D. Atkins, S. I. Mortimer, and J. H. J. van der Werf. 2008. Genetic parameters for carcass and meat quality traits and their relationships to liveweight and wool production in hogget Merino rams. J. Anim. Breed. Genet. 125:205-215. 
Greer, A. W. 2008. Trade-offs and benefits: Implications of promoting a strong immunity to gastrointestinal parasites in sheep. Parasite Immunol. 30:123-132.

Gunia, M., N. Mandonnet, R. Arquet, C. de la Chevrotière, M. Naves, M. Mahieu, and G. Alexandre. 2010. Production systems of Creole goat and their implications for a breeding programme. Animal 4:2099-2115.

Gunia, M., N. Mandonnet, R. Arquet, G. Alexandre, J.-L. Gourdine, M. Naves, V. Angeon, and F. Phocas. 2012. Economic values of production, reproduction and parasite resistance traits for the Creole goat breeding goal. Animal, in press.

Gunia, M., F. Phocas, R. Arquet, G. Alexandre, and N. Mandonnet. 2011. Genetic parameters for body weight, reproduction, and parasite resistance traits in the Creole goat. J. Anim. Sci. 89:3443-3451.

Hoste, H., S. Sotiraki, S. Y. Landau, F. Jackson, and I. Beveridge. 2010. Goat-nematode interactions: Think differently. Trends Parasitol. 26:376-381.

Jackson, F., and J. Miller. 2006. Alternative approaches to controlQuo vadit? Vet. Parasitol. 139:371-384. doi:10.1016/j.vetpar.2006.04.025.

Kahn, L. P., M. R. Knox, S. W. Walkden-Brown, and J. M. Lea. 2003. Regulation of the resistance to nematode parasites of single- and twin-bearing Merino ewes through nutrition and genetic selection. Vet. Parasitol. 114:15-31.

Kaplan, R. M. 2004. Drug resistance in nematodes of veterinary importance: A status report. Trends Parasitol. 20:477-481.

Kemper, K. E., R. L. Elwin, S. C. Bishop, M. E. Goddard, and R. R. Woolaston. 2009. Haemonchus contortus and Trichostrongylus colubriformis did not adapt to long-term exposure to sheep that were genetically resistant or susceptible to nematode infections. Int. J. Parasitol. 39:607-614.

Kominakis, A., G. Nitter, D. Fewson, and E. Rogdakis. 1997. Evaluation of the efficiency of alternative selection schemes and breeding objectives in dairy sheep of Greece. Anim. Sci. 64:453-461.

Kominakis, A., and G. Theodoropoulos. 1999. Selection of dairy sheep in Greece for parasitic nematode resistance: Defining the aggregate genotype and evaluating selection schemes. Anim. Sci. 69:535-542.

Mahieu, M., R. Arquet, T. Kandassamy, N. Mandonnet, and H. Hoste. 2007. Evaluation of targeted drenching using FAMACHAC method in Creole goat: Reduction of anthelmintic use, and effects on kid production and pasture contamination. Vet. Parasitol. 146:135-147.
Mandonnet, N., G. Aumont, J. Fleury, L. Gruner, J. Bouix, J. V. T. Khang, and H. Varo. 1997. Genetic resistance to gastro-intestinal parasitism in Creole goats: Effects of tropical environments on genetic expression of the trait. Prod. Anim. 10:91-98.

Mandonnet, N., A. Menendez-Buxadera, R. Arquet, M. Mahieu, M. Bachand, and G. Aumont. 2006. Genetic variability in resistance to gastro-intestinal strongyles during early lactation in Creole goats. Anim. Sci. 82:283-287.

Olesen, I., A. F. Groen, and B. Gjerde. 2000. Definition of animal breeding goals for sustainable production systems. J. Anim. Sci. 78:570-582.

Perry, B. D., T. F. Randolph, J. J. McDermott, K. R. Sones, and P. K. Thornton. 2002. Investing in animal health research to alleviate poverty. Int. Livest. Res. Inst., Nairobi, Kenya.

Riley, D. G., and J. A. Van Wyk. 2009. Genetic parameters for FAMACHA score and related traits for host resistance/resilience and production at differing severities of worm challenge in a Merino flock in South Africa. Vet. Parasitol. 164:44-52.

Rutten, M. J. M., P. Bijma, J. A. Woolliams, and J. A. M. van Arendonk. 2002. SelAction: Software to predict selection response and rate of inbreeding in livestock breeding programs. J. Hered. 93:456-458.

Rinaldi, L., and G. Cringoli. 2012. Parasitological and pathophysiological methods for selective application of anthelmintic treatments in goats. Small Rumin. Res. 103:18-22.

Safari, A., and N. M. Fogarty. 2003. Genetic parameters for sheep production traits: Estimates from the literature. Tech. Bull. No. 49. NSW Agriculture, Orange, N. S. W., Australia.

Safari, E., N. M. Fogarty, D. L. Hopkins, J. C. Greeff, F. D. Brien, K. D. Atkins, S. I. Mortimer, P. J. Taylor, and J. H. J. van der Werf. 2008. Genetic correlations between ewe reproduction and carcass and meat quality traits in Merino sheep. J. Anim. Breed. Genet. 125:397-402.

Smith, C. 1985. Scope for selecting many breeding stocks of possible economic value in the future. Anim. Prod. 41:403-412.

Williams, A. R., J. C. Greeff, P. E. Vercoe, R. J. Dobson, and L. J. E. Karlsson. 2010. Merino ewes bred for parasite resistance reduce larval contamination onto pasture during the peri-parturient period. Animal 4:122-127. 
References

This article cites 36 articles, 3 of which you can access for free at: http://www.journalofanimalscience.org/content/91/2/572\#BIBL 